\title{
Small doses of morphine and intake of water
}

\author{
FUSUN AKKOK \\ Middle East Technical University, Ankara, Turkey \\ and \\ STEPHANIE A. CZIRR and LARRY D. REID \\ Rensselaer Polytechnic Institute, Troy, New York
}

\begin{abstract}
Rats deprived of water for $19 \mathrm{~h}$ were given an opportunity to drink water for 30 min and for another $4.5 \mathrm{~h}$. Prior to drinking, rats were injected with saline or morphine $(1.0 \mathrm{mg} / \mathrm{kg})$ to test whether morphine's effects persisted when given day after day. Surprisingly, we did not observe that morphine enhanced drinking. Subsequently, when rats were deprived of water for $23.5 \mathrm{~h}$, morphine still did not increase intake. When we continued testing, with a demonstration replicating an experiment in which morphine increased drinking and with other demonstrations, it became apparent that small doses of morphine do not always enhance intake of water.
\end{abstract}

Maickel, Braude, and Zabik (1977) reported that small doses of morphine, as well as other agonists at opioid receptors, increased rats' intake of water. On the other hand, the antagonist naloxone leads to decreased intake of water (Maickel et al., 1977; Stapleton, Ostrowski, Merriman, Lind, \& Reid, 1979). We (Akkok, Manha, Czirr, \& Reid, 1988) recently demonstrated that naloxone persistently reduced water intake across repeated administrations without apparent decrement. Our original purpose, in the present study, was to assess the persistence of effects of small doses of morphine on intake of water. Some of morphine's motivational effects do not show tolerance, for example, morphine's enhancement of pressing for brain stimulation (Bush, Bush, Miller, \& Reid, 1976) and its enhancement of intake of alcoholic beverages (Hubbell et al., 1986). Thus, we were interested in observing morphine's persistence in increasing drinking of water.

The test for morphine's enhancement of water intake with repeated doses is straightforward. Deprived rats are given a limited opportunity to drink daily; half are given morphine and the other half a placebo. Observations are made daily until the effects persist or until the effects wane. The necessary condition for such a test is, of course, for morphine to enhance drinking with the early doses. When we attempted this straightforward experiment, much to our surprise, morphine did not enhance drinking. We continued with the testing until it became apparent that morphine was not going to enhance drinking. Then we engaged various procedures to determine whether

\footnotetext{
We express thanks to Nicholas A. Manha, Jean S. Bestle, and Betty A. Osganian for their help with this work. The work was supported in part by Grant AA06212 from the National Institute on Alcohol Abuse and Alcoholism and in part by funds from the Paul Beer Trust administered by Rensselaer Polytechnic Institute. Address correspondence to Larry D. Reid, Department of Psychology, Rensselaer Polytechnic Institute, Troy, NY 12180 .
}

some small procedural variables might account for the lack of a small-morphine-dose effect on intake of water.

\section{EXPERIMENT 1}

This study consisted of two parts in which morphine was administered over a period of time under different levels of deprivation.

\section{Method}

Subjects and Apparatus. The subjects were 20 male Sprague-Dawley rats purchased from Taconic Farms (Germantown, NY). Their mean weight at purchase was $165.8 \mathrm{~g}(\mathrm{SD}=8.2)$. The rats were individually housed in a room maintained at $24^{\circ} \mathrm{C}$ and with a 12-h daily light cycle beginning at $0900 \mathrm{~h}$. Water was presented in bottles with ballpoint sipping tubes. To measure intakes, bottles were weighed before and after their presentation, with scores corrected for spillage (Hubbell et al., 1986). Body weights were measured every third day.

Procedure. Upon arrival at the laboratory, the rats had a 5-day adaptation period with food and water always available. Then they began a daily regimen of $19 \mathrm{~h}$ of water deprivation, followed by a 30 -min presentation of water, beginning at $1430 \mathrm{~h}$. The subjects were then given water for another $4.5 \mathrm{~h}$.

After 5 days, rats were randomly assigned to two groups of 10 each; one received saline (morphine's vehicle), and the other received morphine sulfate $(1.0 \mathrm{mg} / \mathrm{kg})$. Injections were given subcutaneously $(1.0 \mathrm{ml} / \mathrm{kg}) 15 \mathrm{~min}$ before presentation of water.

During the first and last 3 days of a 16-day period, while the daily regimen continued, all subjects received saline. Across the middle 10 days, half received saline and the others received morphine. After this 16-day phase, the subjects began a new schedule of $23.5 \mathrm{~h}$ of deprivation followed by $30 \mathrm{~min}$ of access to water. After a 2-day adjustment period, the rats were given another series of injections spanning 16 days. The only difference between the two 16-day phases was that the rats were given an additional 4.5-h opportunity to drink following the test session during the first phase, but not during the second.

\section{Results and Discussion}

Across the initial days when all rats received saline, the two groups did not differ reliably in body weight or in the amounts they drank during either the 30-min test or during the subsequent 4.5 -h period. Data for the first 10 days of injections yields $F(1,18)=3.88, p=.06$, 
for the drug effect, suggesting that there is no marked difference in water intake between the two conditions (saline vs. morphine). In fact, morphine subjects drank less water than controls $(M s=10.1$ and $11.0 \mathrm{~g}$ for the morphine group and the saline group, respectively). The groups did not reliably change their intake across days $[F(9,162)=0.78, p=.63]$.

During the second part of the 10 days of injections, the groups differed reliably in their mean water intake [Ms $=10.3$ and $11.4 \mathrm{~g}$ for controls and morphine subjects, respectively; $F(1,18)=4.71, p=.04]$. Across days, saline subjects continued to consume roughly the same amount of water, whereas the morphine subjects tended to increase their intake; however, the interaction term was not a reliable source of variance. Total intake across the two time periods did not reliably differ for the two groups.

Across the 10-day period, the rats continued to gain weight. Initially, the mean saline group weight was $230.2 \mathrm{~g}$, and the mean morphine group weight was $234.9 \mathrm{~g}$. On the last measure of body weight during the 10-day period, the mean saline and morphine groups' weights were 258.7 and $260.8 \mathrm{~g}$, respectively $[F(1,18)$ $=0.11, p=.75]$.

During the last 3 placebo days, both groups consumed more water than they did during the first 3 placebo days. This increase seems to be directly related to the rats' weight gains. Across this second placebo period, analyses of variance of scores of water intake during the first 30-min periods and the subsequent 4.5 -h periods yielded no signs of a reliable difference between groups.

At the beginning of the second phase, when the deprivation schedule was changed (no additional 4.5-h access to water), the groups did not differ in intakes or in body weights across the 3 placebo days. Across the 10 days of injections, the two groups did not differ reliably in intakes $[M s=16.4$ and $15.7 \mathrm{~g}$ for the saline group and the morphine group, respectively; $F(1,18)=2.11, p=.16$ ] The interaction term was not reliable. The rats continued to gain weight throughout this period. During the last 3 days of the second 16-day phase, the mean water intake was 16.7 and $16.9 \mathrm{~g}$ for the saline group and morphine group, respectively $[F(1,18)=0.07, p=.79]$.

\section{EXPERIMENT 2}

Maickel et al. (1977) demonstrated that small doses of morphine, methadone, pentazocine, and meperidine increased drinking in water-deprived rats. In Experiment 1, however, we were unable to observe morphine's enhancement of drinking, except for a small increment associated with the 10-day injection period. To further clarify the effects of morphine at small doses, we decided to directly replicate part of Maickel et al.'s demonstration.

\section{Method}

The subjects were 19 male Sprague-Dawley rats purchased from Taconic Farms (Germantown, NY). Their mean weight at purchase was $295.7 \mathrm{~g}(S D=10.99)$. The laboratory conditions were the same as in Experiment 1.
After habituation to the laboratory, the rats began a daily regimen of $23 \mathrm{~h}$ of water deprivation, followed by a 60 -min test involving presentation of water, beginning at $1415 \mathrm{~h}$. After 5 days, the rats were randomly assigned to four groups, three having 5 subjects each and one having 4 subjects. The first and second groups received saline, and the third and fourth received morphine $(1.0 \mathrm{mg} / \mathrm{kg})$. The second and fourth groups were placed in "drinking cages" during the 60-min test session, as were all rats in Maickel et al.'s (1977) study. All injections were given subcutaneously $(1.0 \mathrm{ml} / \mathrm{kg}) 15 \mathrm{~min}$ before presentation of water. Food was available only in the home cages.

While this daily regimen was continued, all subjects received saline for 3 days. On Day 4 , morphine was given to half of the subjects. The drug day was followed by 3 days of saline for all subjects. Body weights were measured daily.

\section{Results and Discussion}

Across the first 3 placebo days, the two groups scheduled for different dosing did not reliably differ in their water intakes. However, the subjects who remained in their home cages during the test consumed more water than those in the drinking cages $[M s=21.3$ and $18.2 \mathrm{~g}$, respectively; $F(1,16)=8.98, p=.01$ ]. On the drug day, the morphine and the saline groups did not differ in water intake $[F(1,15)=0.09, p=.76]$. The subjects in home cages consumed more water than those in the drinking cages, but the difference was not reliable. Also, the interaction between groups and cage condition was not a reliable source of variance.

\section{GENERAL DISCUSSION}

According to the results of the present experiments, morphine does not increase water intake in deprived rats. Similar results were observed with the following demonstrations: (1) The subjects of Experiment 1 were placed on a schedule of $23 \mathrm{~h}$ of water deprivation, followed by a 60-min test session. For 5 days, half received saline and the others morphine $(1.0 \mathrm{mg} / \mathrm{kg})$. There was no reliable difference in water intake between the two groups. (2) With the same regimen used in Demonstration 1 , one group received saline and the other received a $2.0-\mathrm{mg} / \mathrm{kg}$ injection of morphine for 2 days. The groups did not differ reliably in water intake. (3) For 3 days, a large dose of morphine $(50 \mathrm{mg} / \mathrm{kg})$ was given to some subjects of Experiment 2 to cause them to develop tolerance to the suppressive effects of morphine. The subjects were then split into four groups with different morphine histories and were injected with $1.0 \mathrm{mg} / \mathrm{kg}$ of morphine or saline. Neither in this test nor in a similar subsequent one was morphine effective in increasing intake. (4) The subjects of Experiment 2, when they were in a nondeprived state, were injected with saline or morphine $(1.0 \mathrm{mg} / \mathrm{kg})$. The groups did not differ in intake under the influence of injections. (5) A final demonstration with the subjects of Experiment 2 was designed to observe deprived rats when given the opportunity to take water or a sweetened ethanol solution for $60 \mathrm{~min}$. Morphine increased the intake of ethanol solution $[t(9)=4.89, p<.002]$ and decreased the intake of water $[t(9)=6.23$, $p<.002]$.

All experiments yielded similar results. At small doses, morphine did not substantially increase water intake. Therefore, in our laboratory, we failed to replicate Maickel et al.'s (1977) experiment and found no small-morphine-dose effect on water intake. Morphine does increase intake of a sweetened alcoholic beverage (Reid \& Hunter, 1984; and Demonstration 5), as well as intake of an unsweetened alcoholic solution (Wild, Marglin, \& Reid, 1988).

Recently, Cooper (1988) provided an extensive review of the evidence for opioid involvement in controlling drinking. Antagonists, such as naloxone and naltrexone, reduce intake of water across many experimental procedures. Agonists, such as morphine, however, do not increment drinking. The one report indicating that small doses of morphine incremented intake of water was Maickel et al.'s (1977). The experiments reported here do not support the general idea that small doses of mor- 
phine increment intake of water in the same way that they incremen intake of palatable solutions, a finding similar to that of Cooper (1982), and a finding similar to findings from our studies using flavored substances and water in which total fluid intake is often not modified (there are increments in flavored fluid intake, but decreases in water intake, leaving total fluid intake nearly the same). Large doses of agonists decrease water intake.

As Cooper (1988) pointed out, the lack of a bipolar effect (antagonists producing the opposite effect from that of small doses of agonists) is a serious problem for a conclusion that endogenous opioids are salient to control of water drinking. Given naloxone's effects, however, there is apt to be some opioid-related event extending a bout of water drinking, but what that event is remains unknown.

\section{REFERENCES}

Akkok, F., Manha, N. A., CzirR, S. A., \& Reid, L. D. (1988). Naloxone persistently modifies water-intake. Pharmacology Biochemistry \& Behavior, 29, 331-334.

Bush, H. J., Bush, M. F., Miller, M. A., \& Reid, L. D. (1976). Addictive agents and intracranial stimulation: Daily morphine and lateral hypothalamic self-stimulation. Physiological Psychology, 1, 79-85.

COOPER, S. J. (1982). Effects of opiate antagonists and of morphine on chlordiazepoxide-induced hyperdipsia in the water-deprived rat. Neuropharmacology, 12, 1013-1017.

COOPER, S. J. (1988). Evidence for opioid involvement in controls of drinking and water balance. In R. J. Rodgers \& S. J. Cooper (Eds.), Endorphins, opiates and behavioral processes (pp. 187-216). London: Wiley.

Hubbell, C. L., Czirr, S. A., Hunter, G. A., Beaman, C. M., LeCANN, N. C., \& REID, L. D. (1986). Consumption of ethanol solution is potentiated by morphine and attenuated by naloxone persistently across repeated daily administrations. Alcohol, 1, 1-16.

Maickel, R.P., Braude, M. C., \& Zabik, J. E. (1977). The effects of various narcotic agonists and antagonists on deprivation-induced fluid consumption. Neuropharmacology, 16, 863-866.

ReID, L. D., \& Hunter, G. A. (1984). Morphine and naloxone modulate intake of ethanol. Alcohol, 1, 33-37.

Stapleton, J. M., Ostrowski, N. L., Merriman, V. J., Lind, M. D., \& REID, L. D. (1979). Naloxone reduces fluid consumption in water deprived rats. Bulletin of the Psychonomic Society, 13, 237-239.

Wild, K. D., MARGlin, S. H., \& ReID, L. D. (1988). Small doses of morphine enhance voluntary intake of a solution of only ethanol and water. Bulletin of the Psychonomic Society, 26, 129-131.

(Manuscript received April 12, 1988.) 